\title{
Increasing the efficiency of rice production through the introduction of resource-saving technologies on the example of rice systems in Krasnodar Territory
}

\author{
Igor Prihodko \\ Kuban State Agrarian University named after I. T. Trubilin, 13 Kalinina str., Krasnodar,350044, Russia
}

\begin{abstract}
Rice cultivation is the most resource-intensive production in the Russian agro-industrial sector. Historically, the technology of flooded rice cultivation in thy Krasnodar Territory has remained virtually unchanged for more than 90 years. This is due not only to the biological but also to the technological features of its cultivation. In this connection, the issue of optimizing the production process of rice cultivation is becoming increasingly important every year. Global experience in rice cultivation has determined a further direction of research on optimizing rice cultivation technologies, namely the development of a resource-saving technology for drip irrigation of rice. The pioneering research done by domestic scientists to test drip irrigation of rice in Russia has proved the feasibility and effectiveness of their use. This article proposes a modern resource-saving drip irrigation project for rice, which was tested in OOO "Chernoerkovskoe" in the Slavyanskiy District of the Krasnodar Territory. The authors have proved the efficiency of the proposed rice cultivation technology, resulting in the reduction of irrigation norm, material, labour, energy and technical-technological resources in rice production and crops of rice rotation. The introduction of the new technology has improved not only the biometric indicators of rice, but also the ameliorative condition of soils. Drip irrigation technology makes it possible to cultivate rice outside the rice irrigation systems on land previously used for rain-fed agriculture, which will increase not only the potential area under rice cultivation, but also the geography of rice cultivation in Russia.
\end{abstract}

\section{Introduction}

The increasing scarcity of resources in the world is forcing producers of agricultural products to find new solutions in their production [1-3]. One key way of addressing the challenges of optimizing production is to switch to organic farming, which will minimize the anthropogenic impact on the farmland ecosystem and produce environmentally friendly and high quality agricultural products [4,5]. Rice cultivation is the most resource-intensive production with a high level of anthropogenic pressure [6,7]. Low fertile heavy fused chernozems of rice irrigation systems of Lower Kuban lose their favourable physical properties and become degraded, fused, viscous, gleyed after several decades of rice cultivation by traditional technologies with flooding of rice bays [8]. Maintaining the ameliorative condition of soils of reclamation systems requires large labour, material and energy costs, and the technology of rice cultivation itself requires strict compliance with crop rotations and technology. This is often not respected in the pursuit of super-profits [9]. The bureaucratic barriers and decades-long stereotypes about rice farming as well as the fear of partial or full yield loss during the transition to new technologies are no less important factors hindering the introduction of new resourcesaving technologies in the rice-growing sector in Russia [10]. However, regardless of any obstacles, domestic scientists I. P. Kruzhilin, N.N. Dubenko, M. A. Ganiev, K. A. Rodin and others [11-14] researched and introduced modern resource-saving technologies of rice cultivation in Krasnodar Territory, Volgograd and Rostov Regions. As a result, their implementation has proved the relevance and effectiveness of developing drip irrigation technologies of rice in Russia. Further research on drip irrigation of rice will update existing knowledge on rice cultivation and develop a new direction for rice cultivation $[15,16]$. Accumulation of data will create conditions for the development of information-advisory systems based on mathematical models with simulation modelling of rice production technological process planning and assessment of the cost to perform measures for "smooth" transition of farm to new technology with the exclusion of risks of quality and quantity reduction of harvested rice and crops of rice rotation.

\section{Materials and methods}

Rice cultivation on bays of rice irrigation system under drip irrigation used the following method.

In autumn, in the first year of the implementation of the method of rice cultivation on the lands of the rice irrigation fund with drip irrigation, after harvesting the predecessor, there is one-time production of the following operations: 
- cutting and rebuilding of peripheral bays grooves to a depth of 0.4-0.6 m;

- levelling the surface of the bays;

- basic tilling to a depth of $0.25-0.30 \mathrm{~m}$;

- cleaning of irrigation and drainage canals;

- backfilling the bays rollers to the design marks.

This is followed by the annual spring and autumn work cycle, which includes:

- loosening to a depth of $0.16-0.18 \mathrm{~m}$ followed 8-12 days after the first one by $0.12-0.14 \mathrm{~m}$, disking with simultaneous application and embedding of organic fertilizers to a depth of $0.10-0.12 \mathrm{~m}$ at $40-50$ tonnes per 1 ha of manure or green fertilizer;

- tilling with harrowing and simultaneous application of micronutrients 5-6 days before sowing rice seeds at $\mathrm{N}_{150} \mathrm{P}_{50} \mathrm{~K}_{40}$ in $\mathrm{kg}$ a.m./ha to a depth of $0.10-0.12$,

- rolling and/or levelling the soil surface;

- assembling the drip irrigation system including fertigation system and laying of drip tapes on the soil surface with $20 \mathrm{~cm}$ distance between outlets, diameter and wall thickness of the drip tape $-16 \mathrm{~mm}$ and $0.2 \mathrm{~mm}$, respectively, and drip tape water-output in $1 / \mathrm{h}$ per $1 \mathrm{~m}$ set on condition of providing the required moisture content at a given soil layer for the rice crop rotation, with the distance between drip tapes equals $20 \mathrm{~cm}$; preparing rice seeds for sowing, including their dressing and presowing treatment with growth regulator;

- watering before planting rice with a rate that ensures $100 \%$ moisture content of the lowest moisture capacity in the $0.6 \mathrm{~m}$ layer,

- treating the soil surface with soil herbicides;

- sowing rice at a rate calculated according to soil and climatic conditions, sowing dates of the variety, sowing qualities of the weather conditions and quality of tillage,

- drip irrigation of rice through a drip irrigation system during the vegetation period of rice with the frequency and rate of irrigation corresponding to ensure constant soil moisture of $80 \%$ of the lowest moisture capacity in the $0.6 \mathrm{~m}$ layer,

- fertilizing rice plants: first application after the emergence of buds at the rate of $8 \mathrm{mg}$ of nitrogen per 1 plant, a second application in 2-3 leaf phase at the rate of $10 \mathrm{mg}$ of nitrogen per 1 plant, third application in 4-5 leaf phase at the rate of $12 \mathrm{mg}$ of nitrogen per 1 plant, and in 7-9 leaf phase at the rate of $12 \mathrm{mg}$ of nitrogen per 1 plant,
- spraying rice three times with the biologically active agent at leaf phases 2-3, 6-7 and at the end of the tillering phase before the beginning of the emergence phase,

- treating rice crops with pesticides from the phase of 2 leaves to the tillering phase at intervals of 10-15 days with preliminary soil moistening to $100 \%$ of the lowest moisture capacity in the 0.4 m layer,

- treating rice crops with insecticides during the growing season when pests exceed the economic threshold,

- treating the rice crop twice with fungicides during the emergence phase and again after 20-25 days;

- artificial senescence of rice crops,

- desiccation of rice crops,

- harvesting rice;

- watering before planting of accompanying crops of rice rotation with the provision of necessary and sufficient for the planting of crop moisture and depth of soil moistening through drip irrigation system with the application of mineral fertilizers which norms and terms of application correspond to adopted technology for production of this crop of rice rotation;

- planting of seedlings and/or planting of companion crops of the rice crop rotation with the application of mineral fertilizers, treatment of crops with pesticides, fungicides and insecticides whose rates and terms of application correspond to the adopted technology of production of this crop;

- watering of crops of rice crop rotation through drip irrigation system during vegetation period with periodicity and norm of watering depending on compliance with the condition of providing soil moisture necessary for normal development of culture in the layer of soil, required by the technology of culture production;

- harvesting the crops of the rice rotation;

- removing the drip tape;

- mothballing and dismantling drip irrigation system components, including the fertigation system;

- tilling in two tracks to a depth of 0.06-0.08 m;

- basic tilling to a depth of 0.25-0.3 m.

The annual spring and autumn work cycle are repeated in subsequent years of rice cultivation.

Figure 1 shows the developed method of rice cultivation on the lands of the rice irrigation fund with drip irrigation. 


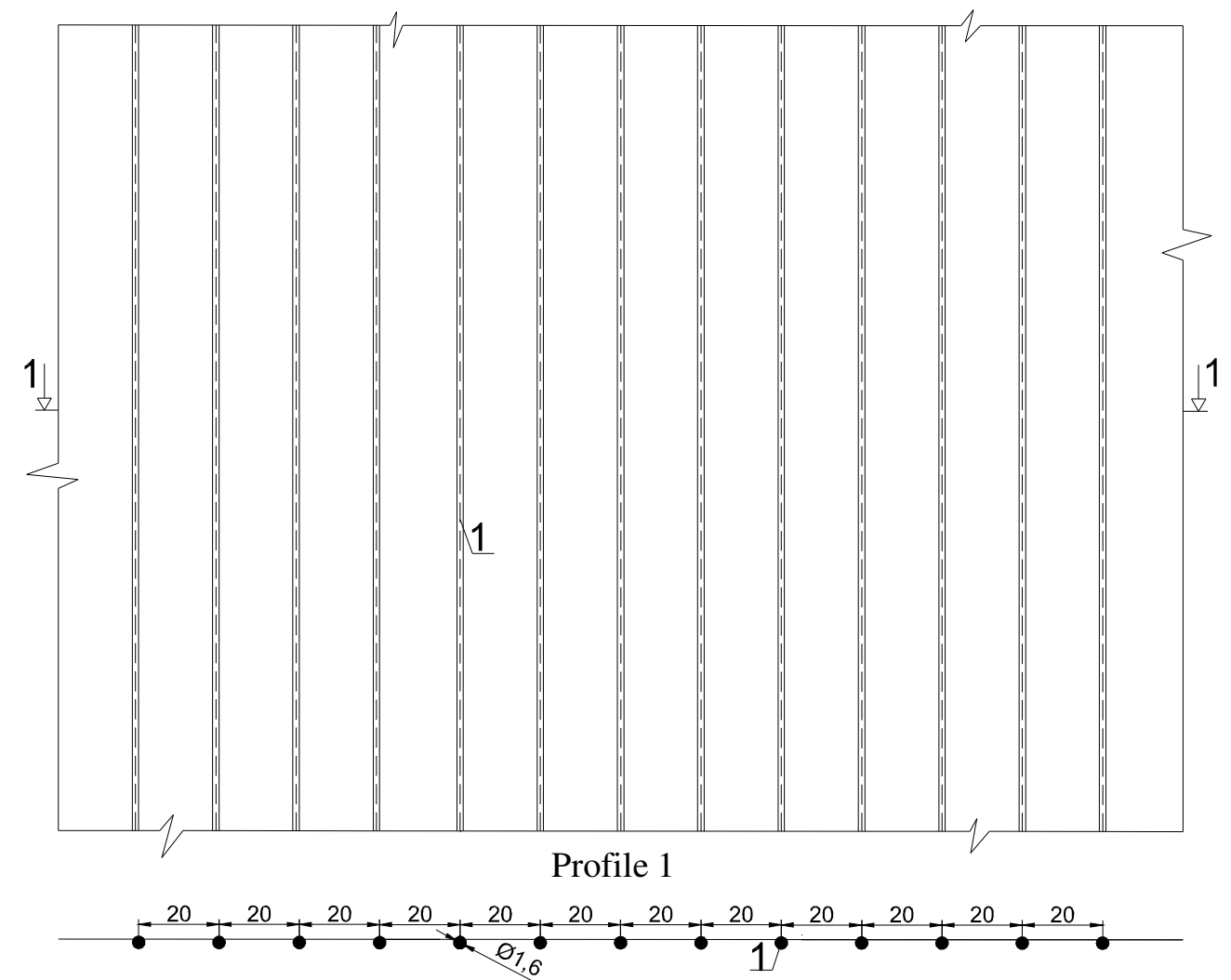

Fig. 1.Technological scheme of cultivation of rice and associated crops of rice crop rotation in OOO "Chernoerkovskoye" of Slavyanskiy district of Krasnodar Territory on surface drip irrigation: 1 - drip tape.

\section{Results and discussion}

The implementation of our drip irrigation technology for rice applied an ecological-adaptive approach, including the possibility of a smooth transition of the farm to new technologies. This result comes through the complex use of previously developed solutions, including assessment of the agro-resource condition of soils on the reclamation scale of the rice irrigation system [13], determination of the average cost of achieving a satisfactory condition by building a mathematical model of water systems functioning [14], determination of the average cost of achieving a satisfactory condition by the system [15] and the use of a simulation model of the economic justification of environmental protection measures in the rice irrigation system [16].

The integrated approach ensures the best possible optimization of the resources available on the farm, their optimization and redistribution in the transition to new resource-saving technologies for rice cultivation.

The method was tested in OOO "Chernoerkovskoe" of Slavyanskiy district (2nd branch) of Krasnodar Territory on the area of 4.5 ha (one rice bay). There was selected an optimal technological process of rice production by drip irrigation with the account of simulation modelling and developed rice crop rotation: 2016: rice + peas, 2017: rice + chickpeas, 2018: rice + soybean, 2019: rice + spring vetch.

Testing the method of rice cultivation by drip irrigation in OOO "Chernoerkivske" in Slavyanskiy district, with an area of 4.5 ha in 2016-2019, has proved the effectiveness of rice cultivation (Figures 24). This is reflected in the improvement of the following indicators: increase in rice yield by $7 \%$, total porosity increased by $14 \%$, the coefficient of structure $C_{s t r}$ increased from 0.90 to 1.07 , soil density decreased from 1.38 to 1.19 , acid-alkaline soil properties changed from slightly acidic - 6.7 to neutral -7.0 , the content of major macroelements in the soil increased: hydrolysable nitrogen by $9.4 \%$, mobile phosphorus by $16.7 \%$, mobile potassium by $31.3 \%$, the content of trace elements in the soil increased: manganese $\mathrm{Mn}$ by $21.7 \%$, copper $(\mathrm{Cu})$ by $40 \%$, zinc $(\mathrm{Zn})$ by $53.8 \%$, cobalt (Co) by $33.3 \%$, molybdenum (Mo) by $32 \%$. 

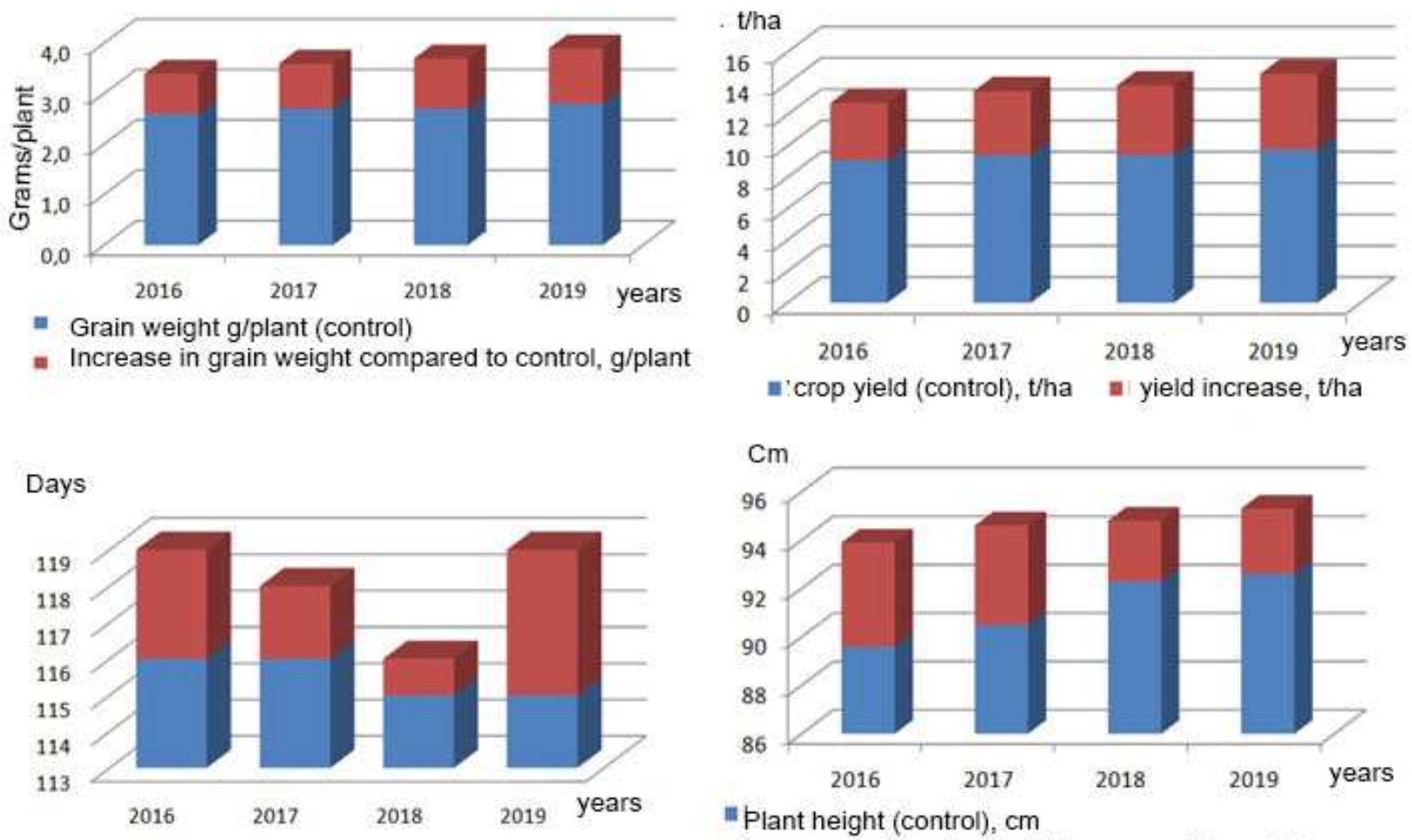

* Vegetation period method, days

$=$ Reduction in the vegetation period (control), days

Fig.2. Changes in quantitative, qualitative and biological characteristics of the rice variety Rapan when cultivated with drip irrigation
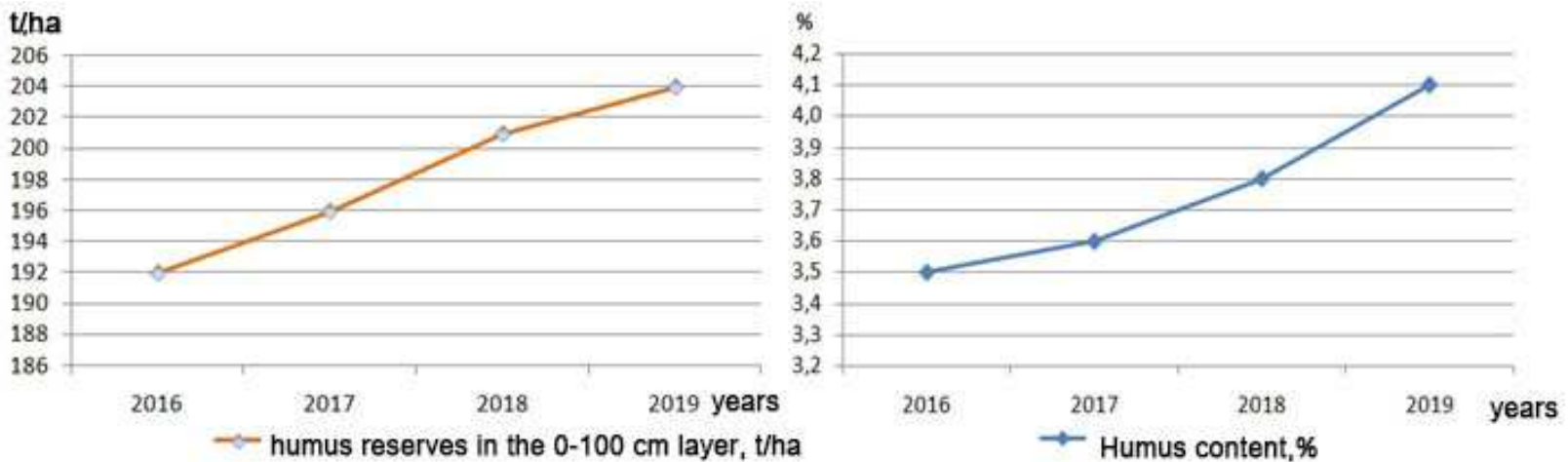

Fig.3. Dynamics of humus recovery with drip irrigation of rice

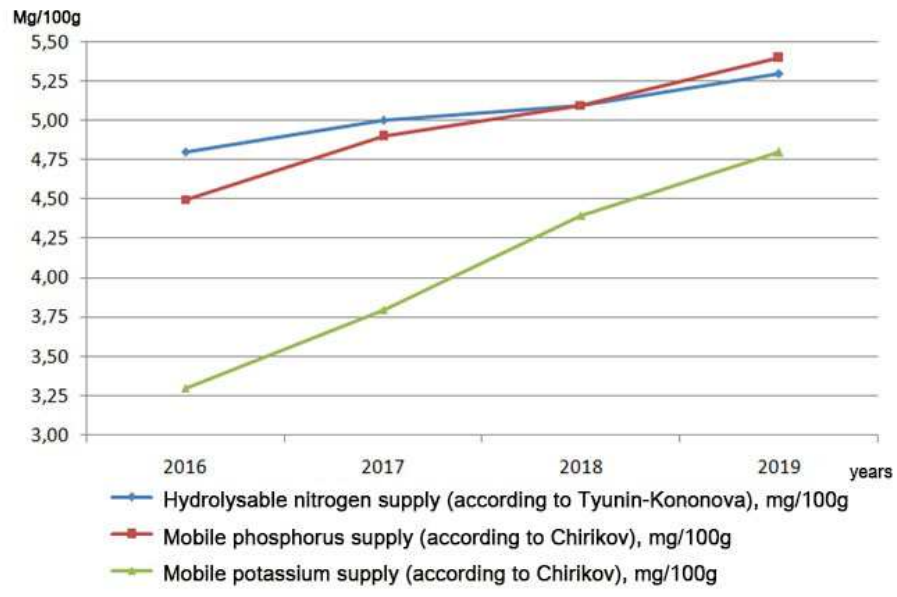

Fig. 4. Dynamics of macronutrient content (NPK) change in the arable horizon when using drip irrigation for rice Corresponding author: prihodkoigor2012@yandex.ru 
Effectiveness of new rice cultivation technology implementation also showed improvement in biometric and quantitative characteristics of rice in comparison with adopted technology (control), the number of spikelets in panicle increased by $7 \%$, the total number of grains per plant $-26 \%$, germination of crops during the study period $99-100 \%$, the survival rate of rice crops was $91 \%$.

The proposed technology allows not only to receive programmed-high yields of high-quality rice grains without reducing ameliorative condition of soils, but also to decrease: irrigation norm on average 5 times in comparison with traditional technology of rice cultivation by flooding; labour input by $20 \%$; rice production cost by average $22 \%$; doses of introduced macro and microelements by average $25 \%$, and also to increase the profitability of rice production by $24 \%$.

\section{Conclusion}

Development of new resource-saving technologies of agricultural production allows developing new software and information-advisory technologies to develop basic normative documentation, which, in turn, enables agro-industry workers to use simulation modelling to calculate the efficiency of agricultural production, considering all modern ecological and reclamation requirements, and on this basis to make timely management decisions on the formation of ecological adaptive technological maps, considering all the available resources. The introduction of such production will significantly reduce the cost of production, increase profitability and yields, as well as the quality of agricultural products without reducing the agro-resource potential of soils.

\section{References}

1. M. Ishfaq, N. Akbar, Sh. A. Anjum, M. A. Growth, Journal of Integrative Agriculture 19 (11), 2656-2673 (2020).

2. H. Chen, W. Zeng, Y. Jin, Y. Zha, B. Mi \& S. Zhang Journal of Hydrology, 591, 125325 (2020).

3. R. Joshia, B. Singh, A. Shukla, Current Plant Biology, 13, 45-52 (2018) doi.org/10.1016/j.cpb.2018.05.001

4. F. Monaco, G. Sali, Agricultural Water Management, 195, 47-57 (2018).

5. S. Majumder, P. Banik, Journal of Environmental Management, 279, 111620 (2021) doi.org/10.1016/j.jenvman.2020.111620.

6. P. Vijayaraghavareddy, Y. Xinyou, P. C. Struik, U. Makarla, Sh. Sreeman, Rice Science, 27 (4), 345-354 doi.org/10.1016/j.rsci.2020.05.009.

7. S. S. Girsang, Jr. T. Q. Correa, J. R. Quilty, P. B. Sanchez, R. J. Buresh Soil and Tillage Research, 202, $104647 \quad$ (2020) doi.org/10.1016/j.still.2020.104647.

8. A. López-Piñeiro, D. Peña, A. Albarrán, J. Sánchez-Llerena, D. Becerra, D. Fernández, S.
Gómez, Journal of Environmental Management, 237, 44-53 (2019)

doi.org/10.1016/j.jenvman.2019.02.058.

9. G. Arbat, S. Cufí, M. Duran-Ros, J. Pinsach, J. Puig-Bargués, J. Pujol, F.R. de Cartagena Water (Switzerland), 12 (6), 1724(2020)

10. M. D. M. Kadiyala, J. W. Jones, R. S. Mylavarapu, Y. C. Li, M. D. Reddy, Agricultural Water Management, 149, 23-32 (2015) doi.org/10.1016/j.agwat.2014.10.019

11. I.P. Kruzhilin, M.A. Ganiev, V.V. Melikhov, K.A. Rodin, S.D. Fomin, N.N. Dubenok IOP Publishing IOP Conf. Series: Earth and Environmental Science 341012100 (2019) doi:10.1088/1755-1315/341/1/012100/.

12. I.P. Kruzhilin, S.D. Fomin, T.A. Gamm, A.A. Mushinskiy IOP Publishing IOP Conf. Series: Earth and Environmental Science 350012037 (2019) doi:10.1088/1755-1315/350/1/012037.

13. I.P. Kruzhilin, A.S. Ovchinnikov, N.V. Kuznetsova, O.V. Kozinskaya, S.D. Fomin, V.S. Bocharnikov, E.S. Vorontsova, Journal of Engineering and Applied Sciences. 13 (13), 4181-4184 (2018)

14. I.P. Kruzhilin, M.A. Ganiev, V.V. Melikhov, K.A. Rodin, N.N. Dubenok, A.S. Ovchinnikov, S.D. Fomin, N.M. Abdou ARPN Journal of Engineering and Applied Sciences, 12 (24), 7118-7123 (2017.).

15. T. Safronova, S. Vladimirov, I. Prikhodko IOP Conf. Series: Earth and Environmental Science 666042063 (2021) doi:10.1088/17551315/666/4/042063.

16. T. Safronova, S. Vladimirov, I. Prikhodko E3S Web Conf., 175, $09011 \quad$ (2020) https://doi.org/10.1051/e3sconf/202017509011. 